\title{
A necessidade urgente de políticas públicas para os arquivos, bibliotecas e museus
}

\author{
Murilo Bastos da Cunha \\ Universidade de Brasília, Faculdade de Ciência da Informação, Brasília, DF, Brasil \\ murilobc@unb.br
}

DOI: https://doi.org/10.26512/rici.v12.n2.2019.23576

Resumo: O editorial comenta a necessidade urgente da existência de políticas públicas voltadas para os arquivos, bibliotecas e museus. Como consequência dessas políticas será possível que os brasileiros possam ter acesso integral a esses tipos de equipamentos culturais. Além disso, são comentados os artigos incluídos no segundo número de 2019 da Revista Ibero-Americana de Ciência da Informação.

Palavras-chave: Brasil. Arquivos. Bibliotecas. Museus. Políticas públicas.

The urgent need for public policies for archives, libraries and museums

Abstract: The editorial comments on the urgent need for public policies focused on archives, libraries and museums. Because of these policies, it will be possible for Brazilians to have full access to these types of cultural equipment. In addition, the articles included in the second issue of 2019 of the Ibero-American Journal of Information Science are commented on.

Keywords: Archives. Brazil. Libraries. Museums. Public policy.

La necesidad urgente de políticas públicas para los archivos, bibliotecas y museos

Resumen: El editorial comenta la necesidad urgente de la existencia de políticas públicas dirigidas a los archivos, bibliotecas y museos. Como consecuencia de esas políticas será posible que los brasileños puedan tener acceso integral a estos tipos de equipamientos culturales. Además, se comentan los artículos incluidos en el segundo número de 2019 de la Revista lberoamericana de Ciencia de la Información.

Palabras-clave: Archivos. Bibliotecas. Brasil. Museos. Políticas públicas.

\section{Caro leitor}

Ao longo das últimas décadas, o Carnaval termina na Quarta-feira de Cinzas. Nesse mesmo dia, e desde 1964, começa uma importante atividade em nosso país. É a Campanha da Fraternidade, projeto anual promovido pela Igreja Católica, durante o período da Quaresma - período de 40 dias que antecede a Páscoa. Sob a coordenação da Conferência Nacional dos Bispos do Brasil (CNBB), essa Campanha tem por objetivo despertar a solidariedade dos católicos e da sociedade como um todo, para buscar soluções para os inúmeros problemas existentes no contexto brasileiro. Em cada ano é escolhido um tema que, por exemplo, pode estar relacionado à juventude, água, saneamento básico, etc. 
Neste ano de 2019 o tema da Campanha da Fraternidade é

"Fraternidade e Políticas públicas", tendo como frase bíblica inspiradora: "Serás libertado pelo direito e pela justiça" (Is 1, 27) e com o objetivo: "Estimular a participação em Políticas Públicas, à luz da Palavra de Deus e da Doutrina Social da Igreja, para fortalecer a cidadania e o bem comum, sinais de fraternidade" (DILLI, 2019).

Segundo Sacchi (2015, p. 1-2), as "políticas públicas tratam do conteúdo concreto e do conteúdo simbólico de decisões políticas, e dos processos de construção e atuação dessas decisões. (...) É uma diretriz elaborada para enfrentar um problema público.

Continuando, o mesmo autor (idem, p. 2) aponta que essas políticas possuem

Dois elementos fundamentais: intencionalidade pública e resposta a um problema público; em outras palavras, a razão para o estabelecimento de uma política pública é o tratamento ou a entendido como coletivamente relevante resolução de um problema.

Para atingir os seus objetivos, políticas públicas devem garantir os direitos da população e reduzir as desigualdades, buscando o ideal de que nenhum cidadão esteja fora do alcance dessa proteção. É vital apontar aqui, que muitos desses direitos já estão inseridos na Carta Magna e em outras normas legais. No item 20 do documento da CNBB é enfatizado que as políticas públicas representam soluções específicas para necessidades e problemas da sociedade. "Ela é a ação Estado, que busca garantir a segurança e a ordem, por meio da garantia dos direitos" (CONFERÊNCIA, 2019).

Mas, o que a Campanha da Fraternidade tem a ver com a área da Ciência da Informação? A resposta é curta e rápida: tem tudo a ver! Apesar de que a Campanha ainda não ter enfatizado o tema "acesso à informação", essa temática precisa ser difundida e, quem sabe, ser escolhida para entrar no rol temático da CNBB, das entidades públicas e privadas, bem como a população em geral. O direito à informação viabiliza a concretização de outros três direitos fundamentais: a democracia, a liberdade de expressão e os direitos sociais.

Vale a pena ressaltar que, o direito à informação consta no artigo 19 da Declaração Universal dos Direitos Humanos (1948); ele também foi contemplado na nossa Carta Magna, que, de acordo com o artigo 5ำ XIV, da Constituição Federal de 1988, "é assegurado a todos o acesso à informação" (BRASIL. Constituição).

A Organização das Nações Unidas (ONU) também considera o acesso à informação fundamental para a construção de sociedades mais inclusivas e sustentáveis. O tema também faz parte da Agenda 2030 para o Desenvolvimento 
Sustentável (NAÇÕES UNIDAS, 2015), que assegura o acesso à informação pública e protege as liberdades fundamentais.

Assim, este editorial convoca as entidades da nossa área de Ciência da Informação a trabalharem para que tenhamos também políticas públicas voltadas para os arquivos, bibliotecas e museus brasileiros. À título de exemplo, é importante difundir a ideia para que seja não repetido o incêndio como o ocorrido no Museu Nacional (CUNHA, 2019), a precariedade do Arquivo Nacional para enfrentar o fogo (ARQUIVO, 2018) e, a nossa maior biblioteca, a Biblioteca Nacional do Rio de Janeiro, a necessidade de se modernizar a sua rede elétrica e climatização (ANGIOLILLO, 2018). É vital que esse movimento seja iniciado rapidamente, as nossas instituições e os nossos usuários não pode esperar mais!

No segundo número da RICl em 2019, foram selecionados para publicação 17 artigos, uma recensão e um documento.

Boa leitura e até o nosso próximo número!

\section{Referências}

ANGIOLILLO, Francesca. Biblioteca Nacional tem que refazer elétrica por segurança de tesouros. Folha de S. Paulo, 10 set. 2018. Disponível em:

https://www1.folha.uol.com.br/cotidiano/2018/09/biblioteca-nacional-tem-que-refazereletrica-por-seguranca-de-tesouros.shtml Acessado em: 10 out. 2018.

ARQUIVO Nacional vive sob risco de incêndio há 17 meses. Agência Estado, 6 set. 2018. Disponível em: https://noticias.r7.com/tecnologia-e-ciencia/arquivo-nacional-vive-sob-riscode-incendio-ha-17-meses-06092018 Acessado em: 10 jan. 2019.

BRASIL. Constituição da República Federativa do Brasil de 1988. Disponível em: http://www.planalto.gov.br/ccivil 03/constituicao/constituicaocompilado.htm Acessado em: 9 de março de 2019.

CONFERÊNCIA NACIONAL DOS BISPOS DO BRASIL. Campanha da Fraternidade 2019. Disponível em: http://www.cnbb.org.br/documentario-especial-sobre-a-campanha-da-fraternidade-2019estimula-a-participacao-dos-cristaos-na-construcao-de-politicas-publicas/ Acessado em: 9 de março de 2019.

CUNHA, Murilo Bastos da. Um museu em chamas: o caso do Museu Nacional do Rio de Janeiro. Revista Ibero-Americana de Ciência da Informação, v. 12, n. 1, p. 1-3, 2018. Disponível em: https://doi.org/10.26512/rici.v12.n1.2019.19354

DECLARAÇÃO Universal dos Direitos Humanos. Disponível em: http://www.mp.go.gov.br/portalweb/hp/7/docs/declaracao universal dos direitos do home m.pdf Acessado em: 9 de março de 2019. 
DILLI, Aloisio Alberto. Campanha da Fraternidade 2019. Disponível em: http://www.cnbb.org.br/campanha-da-fraternidade-2019-3/ Acessado em: 9 de março de 2019.

NAÇÕES UNIDAS. Agenda 2030 para o Desenvolvimento Sustentável. 2015. Disponível em: https://nacoesunidas.org/pos2015/agenda2030/ Acessado em: 10 de março de 2019. 